\title{
VARIASI UKURAN MESH (AI-Si) DAN KARBON TEMPURUNG KELAPA DENGAN MENGGUNAKAN POLYESTER BQTN 157 TERHADAP NILAI PENGUJIAN KEKERASAN
}

\author{
Pramuko Ilmu Purboputro'), Diki Awaluddin²) \\ Jurusan Teknik Mesin, Universitas Muhammadiyah Surakarta \\ Email:pip272@ums.ac.id
}

\begin{abstract}
ABSTRAK
Pada penelitian ini peneliti ingin memahami dan membuat sampel kampas rem sepeda motor dengan menggunakan bahan komposit ramah lingkungan. Bahan yang digunakan dalam penelitian ini yaitu fiberglass, karbon, serbuk Al-Si variasi mesh 50, 60, 100, kalsium karbonat, barium sulfat dan resin polyester dengan katalis sebagai matriks. Kemudian di uji gesek dengan uji kering, uji air, uji air garam, uji oil dan uji minyak rem dengan beban $20 \mathrm{~kg}$ selama 3 jam dan di uji kekerasan menggunakan Durometer dengan standar ASTM D2240. Dari hasil uji kekerasan nilai tertinggi pada variasi Al-Si mesh 100 yaitu 92,7 ShoreD. Hasil pengujian gesek nilai keausan tertinggi pada semua kondisi dari variasi Al-Si mesh 100 yaitu 33,171 mm3/jam, 29,025 mm3/jam, 29,025 mmjam, $30,393 \mathrm{~mm}^{3} / \mathrm{jam}, 37,310 \mathrm{~mm}^{3} / \mathrm{jam}$. Dari hasil pengujian gesek di dapat nilai koefisien gesek nilai tertinggi pada semua kondisi dari variasi Al-Si mesh 100 yaitu 0,7084, 0,6322, 0,6025, 0,6393, 0,6345. Pada foto mikro setelah uji gesek kampas rem variasi mesh 50 mengalami kegagalan bonding adhesive sedangkan variasi mesh 60, 100 dan pasaran $x$ mengalami kegagalan bonding kohesive. Dari hasil pebahasan dapat di simpulkan besar kecil butiran Al-Si mempengaruhi nilai kekerasan, keausan dan koefisien gesek kampas rem.
\end{abstract}

Kata kunci: serbuk Al-Si, karbon tepurung kelapa, polyester

\begin{abstract}
In this study researchers wanted to understand and make samples of motorcycle brake pads using environmentally friendly composite materials. The materials used in this study are fiberglass, carbon, Al-Si powder, mesh variation of 50, 60, 100, calcium carbonate, barium sulfate and polyester resin with catalyst as matrix. Then the friction test with dry test, water test, salt water test, oil test and brake fluid test with a load of $20 \mathrm{~kg}$ for 3 hours and tested for hardness using Durometer with ASTM D2240 standard. From the results of the hardness test the highest value on the variation of Al-Si mesh 100 is 92.7 ShoreD. The highest friction value testing results on all conditions of the variation of Al-Si mesh 100 that is $33.171 \mathrm{~mm}^{3} / \mathrm{hr}, 29.025 \mathrm{~mm}^{3} / \mathrm{hr}, 29.025 \mathrm{~mm}^{3} / \mathrm{hr}, 30.339 \mathrm{~mm}^{3} / \mathrm{hr}, 37.310 \mathrm{~mm}^{3} /$ hr. From the results of friction testing can get the highest value of friction coefficient in all conditions of the variation of Al-Si mesh 100 that is 0.7084, 0.6322, 0.6025, 0.6393, 0.6345 . In micro photos after the brake pads friction test mesh 50 variations have adhesive bonding failure while 60, 100 mesh and market $x$ variations have cohesive bonding failure. From the results of the analysis can be concluded the small size of Al-Si granules affect the value of hardness, wear and friction coefficient of brake pads.
\end{abstract}

Keywords: Al-Si powder, coconut palm carbon, polyester 


\section{PENDAHULUAN}

Dalam hal ini peneliti ingin menggunakan bahan non asbes karena lebih ramah lingkungan. Indonesia, merupakan negara penghasil pohon kelapa terbesar di dunia dan pohon kelapa sendiri memiliki banyak fungsi, salah satunya kegunaan lain tempurung kelapa bisa di gunakan untuk bahan alternatif serat penguat gesek. Karena tempurung kelapa memiliki karakter fisik dan mekanik yang baik yaitu kekerasan dan kerapatan tinggi, serta serapan air yang rendah (Kiswiranti, dkk. 2009).

Aluminium silikon (Al-Si), memiliki daya tahan korosi, abrasi / tahan aus, ringan , koefisien muai rendah dan juga mempunyai kekuatan yang tinggi. Selama ini limbah piston yang pemanfaatannya sebatas pada peleburan ulang (remelting).

Dalam penelitian ini mencari material alternatif kampas rem dengan performa yang baik serta tidak menimbulkan efek buruk bagi lingkungan, Sehingga peneliti menggunakan bahan karbon tempurung kelapa, Al-Si dengan variasi mesh 50,60,100 pada kedua bahan tersebut dan di padukan dengan bahan pengisi dan pengikat serta melakukan pengujian kekerasan dengan standart ASTM D2240, foto mikro, pengujian keausan dan koefisien gesek pada kondisi kering, pengaruh air, pengaruh oil, pengaruh air garam / asam, dan pengaruh oil rem.

\section{Tujuan Penelitian}

1. Pengaruh variasi komposisi kampas rem terhadap nilai kekerasan.

2. Pengaruh variasi komposisi kampas rem terhadap nilai keausan.

3. Pengaruh variasi komposisi kampas rem terhadap nilai koefisien gesek.

\section{Batasan Masalah}

Untuk mengurangi kompleksitas dan pembahasan yang meluas maka lingkup penelitian ini di batasi sebagai berikut :

1. Bahan

Pada penelitian ini bahan yang di gunakan yaitu Al-Si (piston) 83,60 \% Aluminium dan $14,1 \%$ silicon yang sebelumnya telah di lakukan uji komposisi kimia menggunakan uji emmision spectrometer (ASTME-11251) dengan variasi mesh 50,60, dan100,serbuk tempurung kelapa, fiber glass, polyester, serbuk kalsium karbonat, serbuk barium sulfat.

2. Pengujian

Pada penelitian ini di fokuskan pada pengujian kekerasan dengan standar ASTM D2240, foto mikro, pengujian keausan dan koefisien gesek pada kondisi kering, air, air garam, oli, dan oli rem.

3. Variasi bahan
a. $\quad 45 \%$ karbon tempurung kelapa ukuran mesh 50, $5 \%$ (Al-Si) ukuran mesh 50, $15 \%$ fiber glass, $35 \%$ polyester .
b. $45 \%$ karbon tempurung kelapa ukuran mesh $60,5 \%$ (Al-Si) ukuran mesh $60,15 \%$ fiber glass, $35 \%$ polyester .
c. $\quad 45 \%$ karbon tempurung kelapa ukuran mesh 100, $5 \%$ (Al-Si) ukuran mesh 100, 15 $\%$ fiber glass, $35 \%$ polyester .

\section{Tinjauan Pustaka}

Desi Kiswiranti, (2007), Kampas rem berbahan asbestos hanya mampu bertahan pada suhu $200^{\circ} \mathrm{C}$ dan debu dari kampas rem ini sangat beracun yang dapat menyebabkan penebalan dan luka gores pada paru-paru (fibrosis), berbeda dengan kampas rem berbahan non asbestos yang mampu bertahan hingga suhu diatas $300^{\circ} \mathrm{C}$ raah lingkungan dan apabila terkena air daya pengeremannya masih bisa optimal . 
Santoso, dkk. (2016) melakukan penelitian tentang komposisi serbuk tempurung kelapa $20 \%$, serbuk alumunium $40 \%$, resin $40 \%$ memiliki angka yang mendekati kampas pembanding dengan nilai keausan 0,071.10-7 mm2/kg. Komposisi serbuk tempurung kelapa 20\%, serbuk alumunium $40 \%$, resin 40\%memiliki angka yang mendekati kampas pembanding dengan nilai kekerasan 16,8 kgf/mm2. Dengan melakukan variasi komposisi serbuk tempurung kelapa sangat berpengaruh terhadap angka keausan dan angka kekerasan.

Irfan, Pramuko IP, Ngafwan. (2009) melakukan penelitian tentang kampas rem gesek dengan memberikan waktu sintering pada tekanan kompaksi sebesar 10 menit. Keausan suatu bahan komposit semakin besar atau semakin mudah aus dapat dipengaruhi oleh besarnya waktu yang diberikan pada proses kompaksi. Bila waktu penekanannya semakin besar maka tingkat keausan pun juga semakin besar. Nilai kekerasan suatu bahan juga terpengaruh oleh besar waktu penekanan kompaksi yang diberikan dalam proses pembuatan bahan kampas rem. Dalam pembuatan kampas, nilai kekerasan kampas juga berpengaruh dengan semakin besar kompaksi yang dibebankan maka semakin keras pula komposit tersebut. Karena komposit tersebut sendiri dipengaruhi oleh beberapa faktor dalam proses pembuatan dari bahan menjadi komposit dan beberapa penyebabnya yaitu: variasi bahan, beban kompaksi (beban press) yang diberikan serta lamanya beban kompaksi, dan pemanasan (sintering).

\section{METODE}

\section{Diagram Alir Penelitian \\ Bahan dan Alat}

Bahan

1. Barium Sulfat

2. Calsium Karbonat

3. Resin Epoxy

4. Plat Kampas Honda

5. Fiberglass

6. Polyester BQTN 157

7. Karbon Tempurung Kelapa

8. Serbuk Al-Si

9. Cobalt

10. Katalis

Alat

1. Mesin Pres

2. Dies (cetakan)

3. Heater

4. Unit Pengontrol suhu (Therocontrol)

5. Non-contact infrared Thermometer

6. Digital Tachometer

7. Clamp Meter

8. Jangka Sorong

9. Timbangan Digital

10. Oven

11. Blender

12. Mesin Bubut

13. Mesin Frais 
14. Alat Uji Gesek

15. Alat Uji Kekerasan

16. Alat uji Foto Mikro

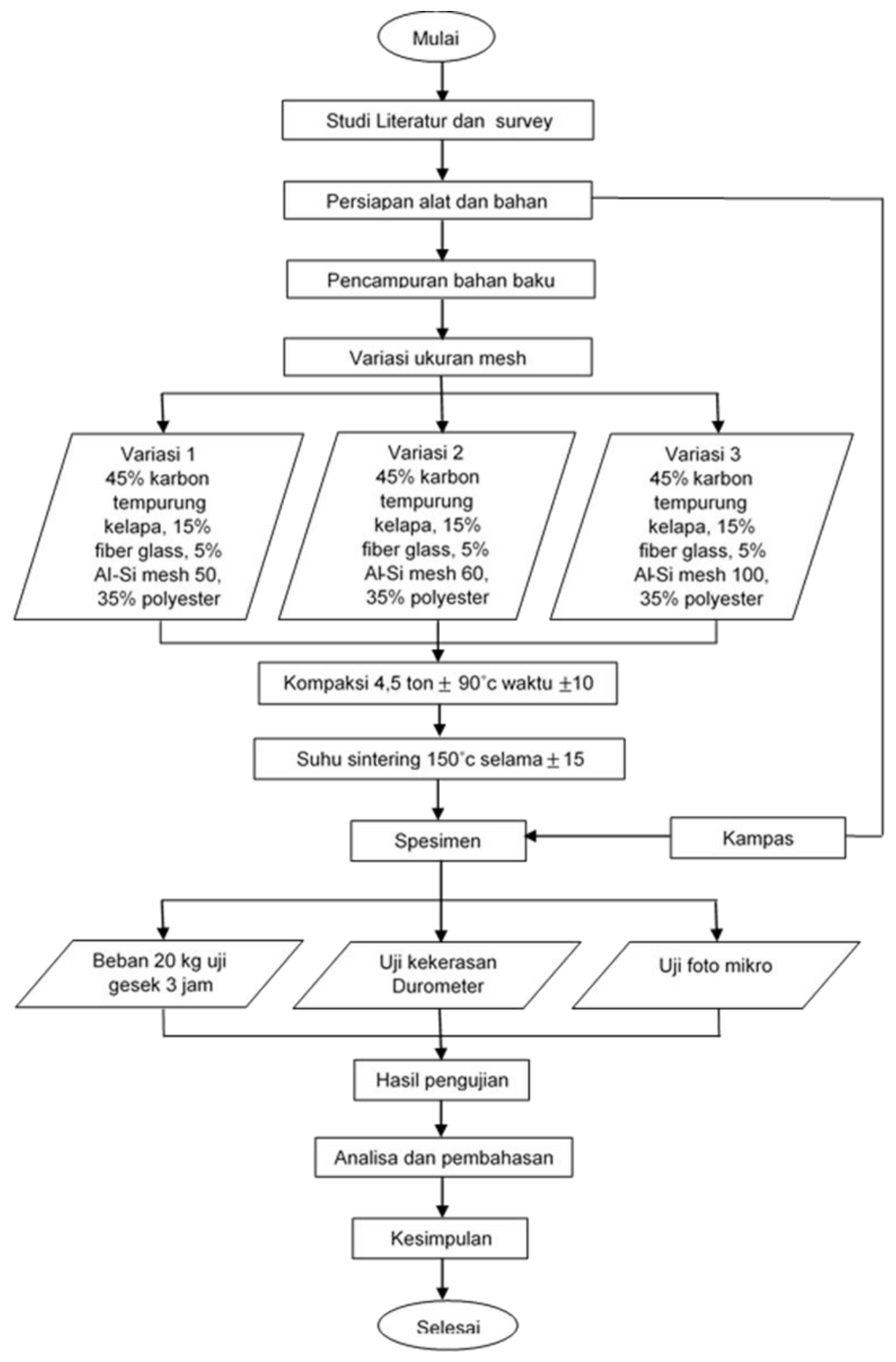

Gambar 1 Diagram alir penelitian

\section{Langkah Penelitian}

Pada penelitian ini menggunakan variasi ukuran besar butir AL- Si sebanyak 30 spesimen. Dari masing-masing jenis variasi di lakukan berbagai pengujian yaitu pengujian kekerasan, pengujian gesek, dan foto mikro. 


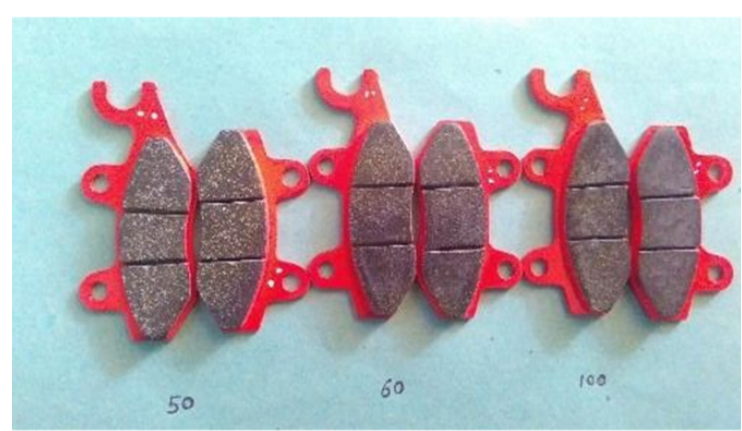

Gambar 2 kampas Rem

1. Mempersiapkan bahan dan alat.

2. Melakukankan penimbangan.

3. Pencampuran bahan-bahan hingga merata kemudian di masukkan ke cetakan yang sudah terpasang plat kampas yang sudah di kasih perekat.

4. Kemudian di pres dengan beban 4,5 ton selama 10 menit dengan suhu $90^{\circ} \mathrm{C}$.

5. Di sintering dengan suhu $150^{\circ} \mathrm{C}$ selama 15 menit, setelah ini di lakukan pengujian kekerasan, pengujian gesek dan foto mikro dan diambil data dari pengujian.

Mencari nilai keausan

Keausan $=\frac{(\mathrm{T} 0-\mathrm{T} 1) \mathrm{A}}{t}$

dimana : To = tinggi awal kampas $(\mathrm{mm})$

$\mathrm{T} 1$ = tinggi akhir kampas (mm)

$\mathrm{T}=$ lama waktu pengujian (jam)

A $=$ luas permukaan kampas $\left(\mathrm{mm}^{2}\right)$

Sedangkan mencari nilai koefisien

$\mu=\frac{T}{2 \times \mathrm{Fn} \times \mathrm{r}}$

dimana : $\mu=$ koefisien gesek $\mathrm{T}=$ Torsi (N.m), Fn $=$ beban , (N) $\mathrm{r}=$ jarak dari titik pembebanan ke kampas (m)

HASIL DAN PEMBAHASAN

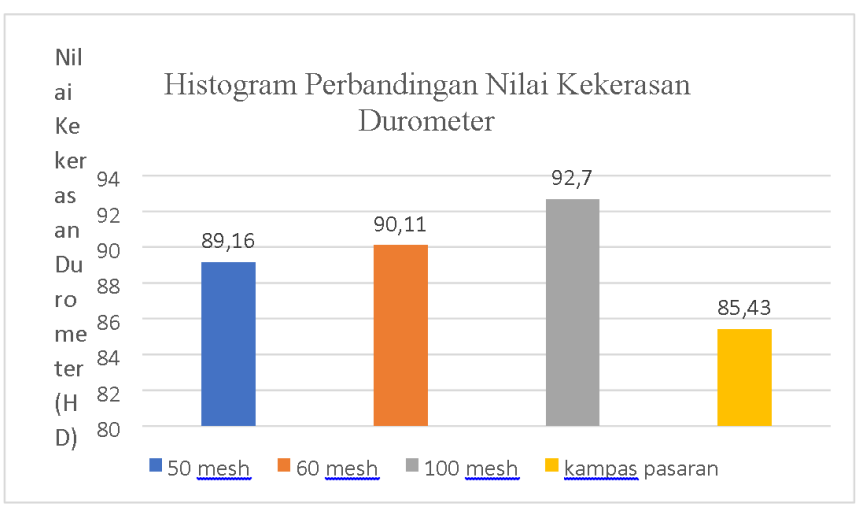

Gambar 3 Histogram Perbandingan Kekerasan Durometer Shore D 


\section{PENUTUP}

\section{Kesimpulan}

Nilai kekerasan dari kampas rem Al-Si dengan variasi mesh 100 memiliki nilai paling tinggi yaitu 92,7 skala shore D, sedangkan nilai kekerasan pada mesh 60 dengan nilai 90,11 shore D, nilai kekerasan pada mesh 50 dengan nilai 89,16 shore $\mathrm{D}$, dan pada nilai kekerasan kampas pasaran x memiliki nilai terendan dengan nilai 85,43 shore D dari hasil tersebut di simpulkan besar butiran Ai-Si mempengaruhi nilai kekerasan kampas rem.

\section{DAFTAR PUSTAKA}

[1] ASTM D2240-Durometer Hardness.

[2] Blau, P. J., 2009, Friction Science and Technology, CRC Press, New York.

[3] Calister, Mc. Graw Hill. 2005. Material Science, London.

[4] German. R.M., 1984. Powder Metallurgi Science. Metal Power Federation. Pricenton, New Jersey.

[5] Gibson, R.F., 1994. Principle Of Composite Material

[6] Mechanic. McGraw-Hill Interrnational Book Company, New York.

[7] Irfan, Pramuko, Ngafwan.,(2009) Pengaruh Variasi Tekanan Kompaksi Terhadap Ketahanan Kampas Rem Gesek Sepatu. Laporan tugas akhir fakultas teknik mesin UMS, 2009, Surakarta.

[8] Kiswiranti, Sugiarto, Hindarto N, Sutikno., (2009) Pemanfaatan Serbuk

[9] Tempurung Kelapa Sebagai Alternatif Serat Penguat Bahan Friksi NonAsbestos Pada Kampas Rem Sepeda Motor. Semarang : jurnal jurusan fisika, fakultas matematika, dan ilmu pegetahuan alam. Universitas Negeri Semarang.

[10] Kiswiranti Desi., (2007) Pemanfaatan Serbuk Tempurung Kelapa Sebagai Alternatif Serat Penguat Bahan Friksi Non-Asbestos Pada Pembuatan

[11] Kampas Rem Sepeda Motor. Semarang : skripsi fisika, Universitas Negeri Semarang.

[12] Santoso, Estriyanto Yuyun, Wijayanto Danar Susilo., (2016) Pemanfaatan

[13] Campuran Serbuk Tempurung Kelapa Dan Alumunium Sebagai Material Alternatif Kampas Rem Sepeda Motor Non-Asbestos. Laporan tugas akhir program studi teknik mesin UNS, Surakarta.

[14] Setiaji, Rahman. 2009. Pengujian Keausan. (www.scribd.com). Diakses pada tanggal 5 Agustus2017.

[15] Smith, William F. (1990). Principles of Material Science And Engineering, second edition. Mc. Graw Hill Publishing Company.

[16] http://www.otosentrum.com/teknologi-sistem-rem http://m-edukasi.kemdikbud.go.id www.scribd.com/doc/21704473/uji-keausan 